\title{
THE PHOTOGRAPHIC EMULSION; THE SILVER ION-GELATIN EQUILIBRIUM
}

\author{
By Burt H. Carroll and Donald Hubbard
}

\section{ABSTRACT}

Electrometric determination of silver ion activity in silver nitrate-gelatin solutions showed strong selective combination of silver ion with gelatin. This decreases with increasing hydrogen ion concentration, buc does not vanish on the acid side of the isoelectric point. Similar measurements in silver bromidemmonia-gelatin solutions detected no combination of gelatin with the silverammonia ion. The hydrolysis of silver bromide and chloride in thoroughly washed emulsions was calculated from the electrometric data and verified by direct experiment.

CONTENTS

Page

I. Introduction ion concentrations. . . .

1. Apparatus.

2. Silver ion coucentrations

3. Discussion

III. Equilibrium in silver bromide-ammonia-gelatin solutions....

IV. The composition of emulsions washed to equilibrium

V. Summary .

\section{INTRODUCTION}

The buffer action of gelatin-its capacity to combine with either acids or bases and reduce the change in hydrogen ion concentration resulting from the addition of the acid or base to the solution-is well known and important in several types of photographic phenomena. The object of this paper is to call attention to a similar capacity of gelatin for combination with silver ions, and some of its photographic consequences.

It should first be pointed out that in the combination of gelatin with acids or bases, the hydrogen or hydroxyl ions are combined in a manner which may under most conditions be considered unique. When, for example, gelatin is added to a solution of hydrochloric acid, the activity of the hydrogen ion as determined by any of the wellknown methods is greatly reduced, while that of the chlorine ion is unaffected in dilute solutions. If such a mixed solution is separated by a suitable membrane from water or an electrolyte solution, the behavior of the chlorine ion may be predicted on the assumption that it is held to the gelatin only by electrostatic forces, while the gelatinhydrogen ion complex must be treated as a single new unit. This applies whether we believe with Loeb, that gelatin acts as an amphoteric electroly te and the complex is a new ion, differing from other ions mainly by nondiffusibility, or whether we adopt the view supported by Bancroft that the gelatin units are a separate phase, to which the 
hydrogen ion is selectively adsorbed. The combination with the hydroxyl ion of bases is of the same type as with the hydrogen ion and apparently of about the same strength. On the alkaline side of the isoelectric point, the gelatin-hydroxyl ion complex will therefore hold any available cation at least electrostatically. Loeb ${ }^{1}$ has given striking qualitative demonstrations of these phenomena. Using the photochemical reduction of silver ion by gelatin as a test for its presence, it is readily shown that this ion can be washed completely out of gelatin on the acid side of the isoelectric point, but is retained at $\mathrm{pH}$ greater than 4.7.

Recent investigations have disclosed numerous cases in which this simple treatment is invalidated by appreciable combination of other ions with the gelatin in such a manner as to reduce their activity. The combination with cations extended well to the acid side of the isoelectric point, and that of the anions to the alkaline side. Northrop and Kunitz ${ }^{2}$ have furnished the most data on this subject, using concentration cells, and an ingenious method based on the measurement of membrane potential for those ions for which no electrode was available.

Most of their measurements were made at the isoelectric point, where no combination of the gelatin with any ion is to be expected on the simple theory, but they also studied the effect of varying hydrogen ion concentration. No combination of $\mathrm{Na}^{+}$or $\mathrm{K}^{+}$was detected, but a single determination with silver nitrate showed appreciable combination of the silver ion. All the bivalent cations tested $\left(\mathrm{Cu}^{++}\right.$, $\mathrm{Ca}^{++}$, and $\mathrm{Mg}^{++}$) were found to combine with the gelatin in amounts varying with their concentration and the $\mathrm{pH}$, up to $9 \times 10^{-4} \mathrm{gram}$ equivalents per gram of gelatin. This maximum not only agrees with that obtained by Hitchcock ${ }^{3}$ for hydrogen, but in mixtures of copper salts and acids the total of combined hydrogen and copper ions was approximately constant at this value. The combined copper was appreciable even at $\mathrm{pH} 2$, although for the same activity it was very much less than the combined hydrogen. The maximum combination with both copper and hydrogen was reduced to $5 \times 10^{-4}$ gram equivalent per gram of gelatin by deaminizing. $\mathrm{Al}^{+++}$and $\mathrm{La}^{+++}$reached a maximum of about $5 \times 10^{-4}$ gram equivalent per gram gelatin, although the measurements were carried up to molar solutions; this, like the equivalence of hydrogen and copper, is strong evidence for true chemical combination, since the adsorption of trivalent ions would be expected to be greater than that of bivalent ions.

The measurements with copper were not carried to the alkaline side of the isoelectric point, but those with calcium covered a range of $\mathrm{pH} 2.5$ to 10 . Northrop and Kunitz state that "the value (of combined calcium) rises rapidly as the solution becomes less acid and remains approximately constant on the alkaline side of $\mathrm{pH} 4.7$," but to the writers their data are more consistent with a continuous increase with $\mathrm{pH}$.

No combination of nitrate or sulphate ion was detected, but conbination with chloride ion up to $3 \times 10^{-4}$ gram equivalent per gram

1 Loeb, Proteins and the Theory of Colloid Behavior.

Northrop and Kunitz, J. General Physiology, vol. 7, p. 25, 1924; vol. 9, p. 351, 1926; vol. 11, p. 481 ; 1928.

- Hitchcock, J. General Physiology, vol. 12, p. 495; 1929. 
of gelatin was reported in the more concentrated solutions $(0.1 \mathrm{M}$ or more).

The combination of silver ion and gelatin has been investigated in other cases. Pauli and Matula, ${ }^{4}$ using concentration cells, found depression of silver ion concentration on adding gelatin, but their gelatin was not deashed and they give no data on $\mathrm{pH}$.

There have been two investigations in photographic laboratories. Rawling and Mitchell, ${ }^{5}$ working on methods of determination of soluble bromide in emulsions, found that they extracted more than should have been present. The effect was greater in silver chloride emulsions and absent in those of silver iodide. They infer from this the existence of a silver gelatin complex in amounts varying with the silver ion concentration.

Schmidt and Pretschner, ${ }^{6}$ after numerous analyses of photographic emulsions for nonhalide silver, have concluded that the excess silver found in thoroughly washed emulsions was formed during the washing process. They found that the excess was proportional to the solubility of the silver halide, and postulate an equilibrium between the silver halide and silver-gelatin complex depending on the relative solubilities.

One explanation for selective combination of silver ion with gelatin lies in the stability of silver ion-amino complexes. Northrop and Kunitz ${ }^{7}$ predicted the combination of copper ion with gelatin on this basis, and apparently had the same idea in mind in their reference to the "expected" combination with silver ion. If this theory is correct, there should be no selective combination of the $\mathrm{Ag}\left(\mathrm{NH}_{3}\right)_{2}{ }^{+}$ ion with gelatin, since the affinity of the silver for amino nitrogen is satisfied. This prediction was verified by experiment. If the analogy with the silver ammonia complex is complete, it involves combination of neutral gelatin molecules with silver ions, to form new positively charged complexes. The effect of hydrogen ion concentration would then be ascribed to a change in the free $\mathrm{NH}_{2}$ groups with which the silver combines. Assuming the existence of peptide linkages

$$
\stackrel{\mathrm{O}}{\mathrm{H}} \underset{-\mathrm{C}-\mathrm{N}-}{1}
$$

in the gelatin, which might be opened by alkali to form

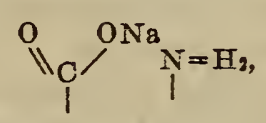

the effect would be in the right direction.

Another alternative is the formation of a silver gelatinate entirely analogous to the sodium gelatinate of Loeb's theory, but distinguished from it by insolubility. The coagulation of proteins by silver salts is evidence for this view. Silver gelatinate would be subject to hydrolysis decreasing with increasing alkalinity. Its existence on the acid side of the isoelectric point is inconsistent with the simple theory as developed by Loeb. However, the isoelectric point represents an

Paull and Matula, Biochem. Zeit., vol. 80, p. 187; 1917.

Rawling and Mitchell, Proc. 8th Int. Cong. of Phot. Abstract in Phot. Ind. vol. 29, p. 905; 1931.

H. H. Schmidt, Proc. 8th Int. Cong. of Phot. Abstract in Phot. Ind. Vol. 28, p. 906; ig31.

See footnote 2. 
equality between the two forms of ionized gelatin; it is not necessarily true that both are equal to zero. It is possible that they are in an equilibrium like the ions of water, with a rapid change in proportions at the isoelectric point like that of the ions of water at the neutral point.

\section{EQUILIBRIUM IN GELATIN-SILVER NITRATE SOLU- TIONS AT VARYING HYDROGEN ION CONCENTRATIONS}

\section{APPARATUS}

The combination of silver ion and gelatin was studied by making electrometric measurements of silver ion concentration in mixed solutions of gelatin and silver nitrate. Further experiments in silver bromide-gelatin emulsions, which were tested photographically as well as chemically, will be described in a separate communication.

All determinations were made at $30.0^{\circ} \mathrm{C}$., using a simple air thermostat. This was a cubical box, 2 feet on edge, lined with heat insulating board on all sides but the front. The door in the front was provided with a double glass window, coated with orange lacquer, which excluded practically all radiation of wave length less than 520 $\mathrm{m} \mu$. This precaution was probably unnecessary, as the cell was illuminated only by relatively dim artificial light, but for measurements of silver ion concentrations in photographic emulsions the possibility of error from photolysis was not to be disregarded. The air was circulated in the thermostat by a blower of 55 cubic feet per minute capacity. By making the bulb of the thermoregulator a grid of $10 \mathrm{~mm}$ tubing placed across the inlet of the blower, and using a heater of fine bare wire in the outlet tube, lag was reduced so that fluctuations as measured by a mercury thermometer were less than $0.02^{\circ}$; all measurements were made at $30.0^{\circ} \pm 0.1^{\circ}$.

The electrical measurements were made with a Leeds and Northrup "student" potentiometer, calibrated in the resistance section of this bureau and found to be accurate to 0.1 millivolt. The galvanometer was the Leeds and Northrup type 2500 e, designed for electrode work.

A $0.1 \mathrm{~N}$ calomel electrode was used for reference. This was connected to the silver electrode by a salt bridge somewhat modified from that of Clark. ${ }^{8}$ The arrangement, which is shown in Figure 1, was designed primarily for electrometric titrations, but was found suitable for potential measurements. The calomel electrode vessel was of the Clark ${ }^{9}$ type, but the upturned tip of the connecting tube was replaced by a short piece of heavy walled tubing, about $1.5 \mathrm{~mm}$ bore. This passed through a rubber stopper, along with the $T$ tube of heavy walled $1.5 \mathrm{~mm}$ tubing which completed the bridge. The whole apparatus was supported so that it could be lifted and swung to one side. In making connections, the cup which fitted over the rubber stopper was nearly filled with the ammonium nitrate solution. It was then forced up until it made a tight joint with the stopper; ammonium nitrate solution was forced out through the $T$ tube, filling it. The cell and bridge were then swung over so that the upturned tip of the bridge could be lowered into the solution under test, which was ordinarily contained in a beaker with a mechanical stirrer.

8 W. Clark, J. Chem. Soc., p. 749; 1926.

- W. Mansfleld Clark, The Determination of Hydrogen Ions, 2d edition, p. 194, E. 
There was no indication that chloride from the calomel electrode diffused through the bridge even over a period of hours. Potentials were reproducible to less than one millivolt. They were not appreciably improved by the use of a wider $(5 \mathrm{~mm}$ ) tip on the connecting tube.

The electrodes used for the silver ion-gelatin equilibrium were $1 \mathrm{~mm}$ wires of pure silver, annealed and frequently cleaned with cyanide

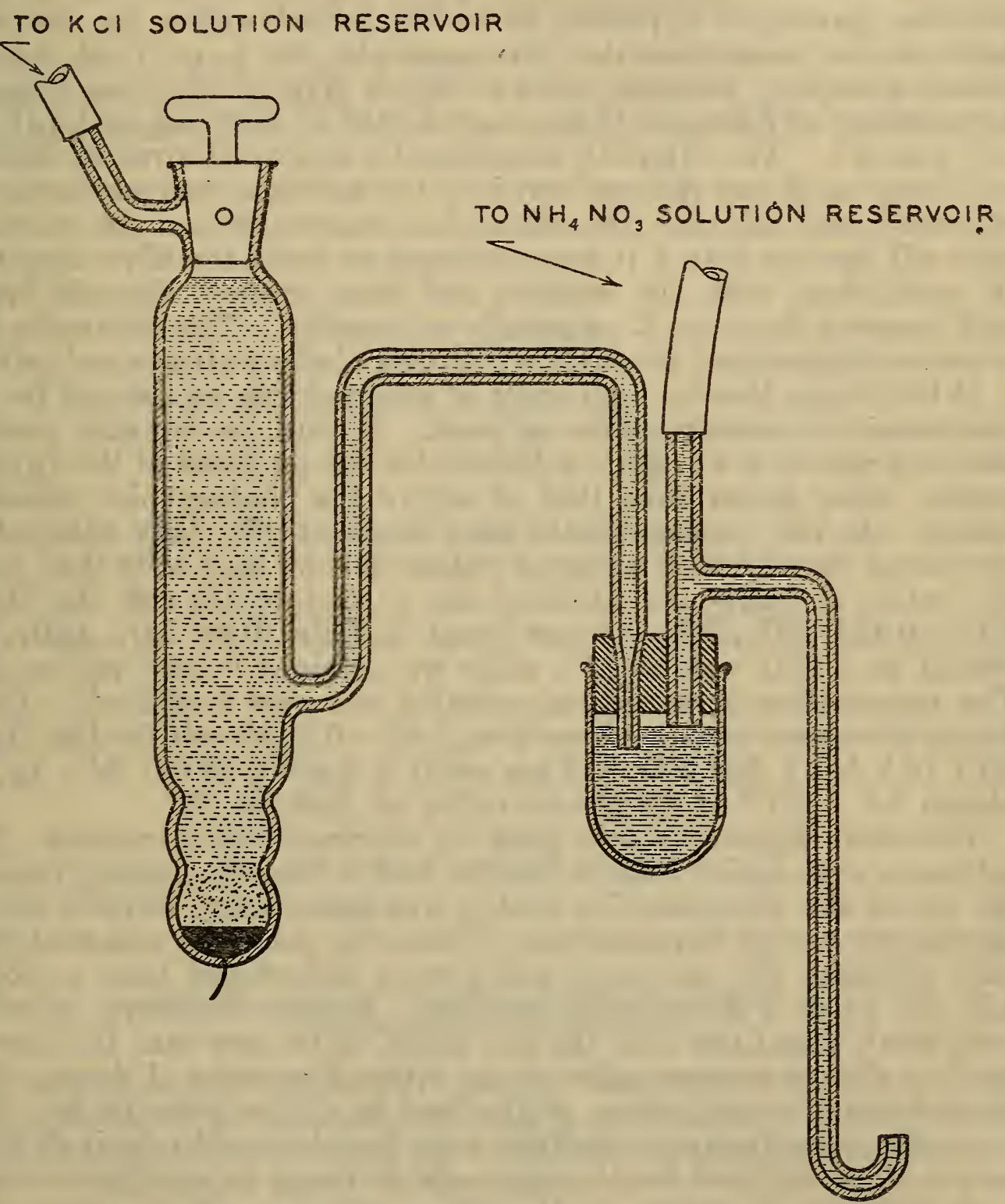

FIGURE 1.-Calomel elecirode and salt bridge for determination of silver ion concentration

solution and hot water whenever they became appreciably sluggish. They checked within 0.5 millivolt or less. The silver wires were sealed into glass tubes with de Khotinsky cement or ceresin so that the metal was completely under the surface of the liquid. For some of the earlier work (emulsions 6-83 to 86) silver plated platinum wires were used; these were also reproducible to 0.5 millivolt, but were somewhat slower to reach equilibrium. For determinations 
of bromide ion concentration in other solutions and for all measurements in emulsions, the electrodes were momentarily made anode in a dilute bromide solution and washed before use. With this treatment the electrodes reached equilibrium with the solution much more rapidly.

Fifteen per cent ammonium nitrate solution was used in the salt bridge, saturated potassium chloride being obviously out of the question for measurements of silver ion concentration. Liquid junction potentials appeared to be eliminated within the limits of error in the measurements. For example, the e. m. f. of the cell changed only 0.7 millivolt when $0.0100 N \mathrm{KBr} \mathrm{pH} 6.9$, was replaced by mixtures of $\mathrm{KBr}$ and $\mathrm{H}_{2} \mathrm{SO}_{4}$, each $0.0100 \mathrm{~N} \mathrm{KBr}$ but with $\mathrm{pH} 5.2$, 3.0 , and 2.1. The $\mathrm{NH}_{4} \mathrm{NO}_{3}$ introduced a source of error in alkaline solutions, as, if any diffused out into the solution, free ammonia was liberated and affected the silver ion concentration. In mixtures with $\mathrm{pH}$ greater than 8 , it was necessary to bring the silver electrode to equilibrium with the solution and then connect the salt bridge and measure the e. $\mathrm{m}$. f. as rapidly as possible. The electrodes also were readily poisoned in alkaline mixtures of silver nitrate and gelatin.

It is obvious that no high order of accuracy can be claimed for the electrometric measurements as such. It will be equally obvious that this accuracy was quite sufficient for the purposes of this investigation, being better than that of any of the photographic measurements. As our measurements were made at $30^{\circ}$, they can not be compared directly with accepted values, but we may note that, using the values of Lewis and Storch, ${ }^{10}$ the e. m. f. of the cell $\mathrm{Hg}, \mathrm{HgCl}$, $\mathrm{KCl}(0.1 M) \| \mathrm{NH}_{4} \mathrm{NO}_{3}$ (15 per cent) $\| \mathrm{HBr}(0.01 M), \mathrm{AgBr}, \mathrm{Ag}$ should be 0.1411 volt at $25^{\circ}$, while we obtained 0.1405 volt at $30^{\circ}$. The temperature correction is probably not over 1 millivolt. Combining the above value with an e. m. f. of -0.2820 volt for $\mathrm{Hg}, \mathrm{HgCl}$, $\mathrm{KCl}(0.1 M) \| \mathrm{NH}_{4} \mathrm{NO}_{3}$ (15 per cent) $\| \mathrm{AgNO}_{3}(0.001 M), \mathrm{Ag}$, we obtain $9.6 \times 10^{-7} \mathrm{M}$ for the solubility of $\mathrm{AgBr}$ at $30^{\circ}$.

The same apparatus was used for electrometric titrations. The solutions were added from a burette with a long tip passing through the top of the thermostat so that it was unnecessary to open the air thermostat during the titration. While the potential was read after each addition, the end point was always determined from a plot of $\Delta E / \Delta v$, as in a differential titration. It was necessary, in work with small quantities near the end point, to be sure that the burette reading always corresponded to an integral number of drops, since the volume of a single drop might lead to a large error in $\Delta v$. The necessary potentiometer readings were found to add relatively little to the time required for the electrode to come to equilibrium after each addition of solution, so that this method was little slower than a differential titration, while it had a very real advantage in that the silver ion concentration indicated clearly the approach of the end point. This last was especially useful for titration of a solution for both bromide and chloride. The solutions were stirred continuously by a small mechanical stirrer belted to a motor outside the thermostat. The belt drive was convenient from the standpoint of space, but it was necessary to ground the stirrer carefully to avoid error from static charges.

14 Lowis and Btorch, J. Am. Ohom. Soc., vol, 39, p. 2544; 1917. 
Hydrogen ion concentrations were measured at $30^{\circ}$ in the same thermostat, using a saturated calomel electrode and a bubbling hydrogen electrode. A quinhydrone electrode was also used on some of the acid mixtures. As neither can be used in the presence of silver ions, the $\mathrm{pH}$ of emulsions was determined colorimetrically by comparison with standard buffer solutions after the emulsions had been cleared by centrifuging.

\section{SILVER ION CONCENTRATIONS}

The gelatin used in these experiments was known to have been made from limed calfskin stock. It was deashed by the method of Northrop and Kunitz, ${ }^{11}$ but as the conductivity of the gelatin after

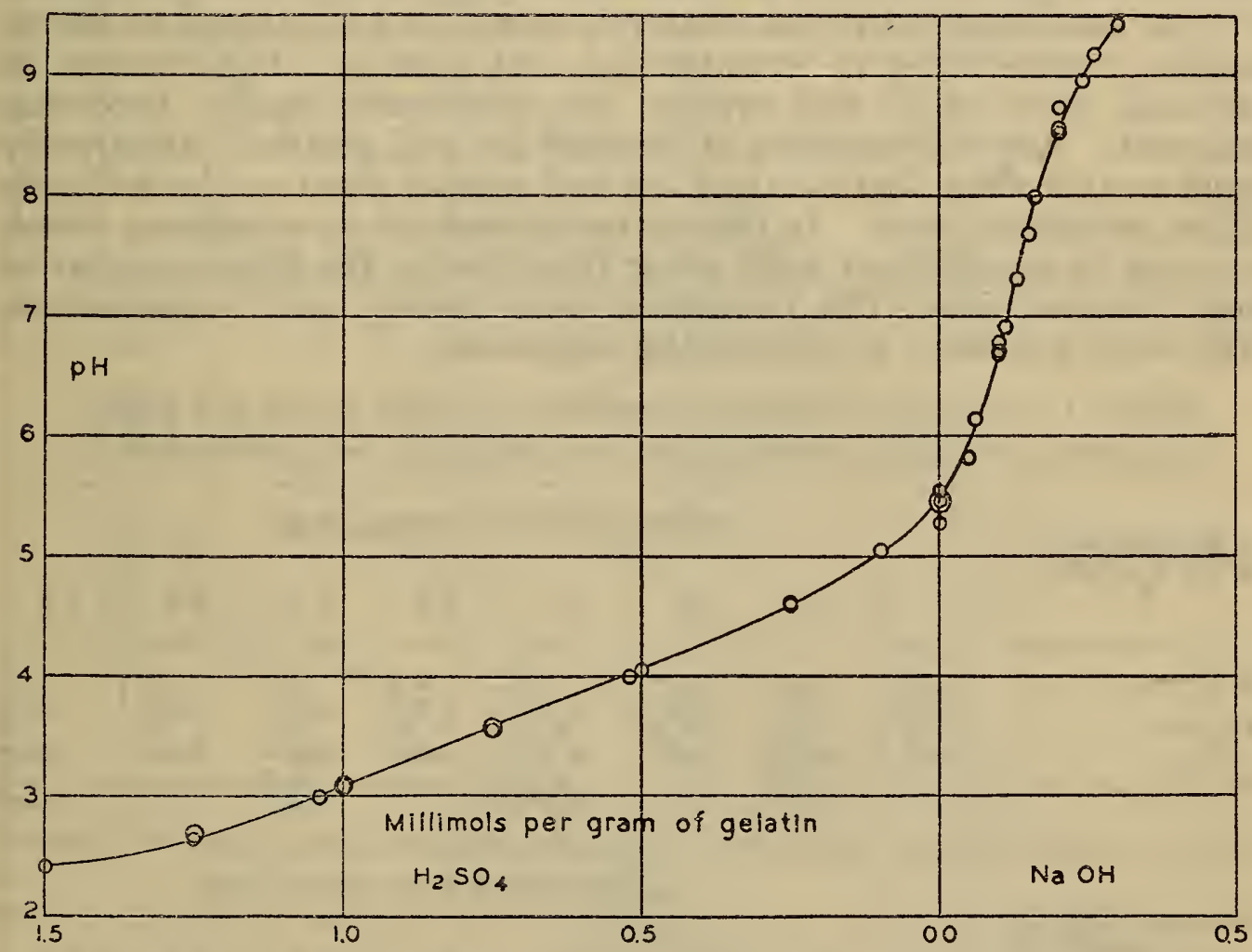

FIgURE 2.-Titration curve of isoelectric gelatin used in experiments, at a concentration of $1.00 \mathrm{~g}$ per $100 \mathrm{ml}$

the recommended number of washings was somewhat high $\left(7 \times 10^{-5}\right.$ reciprocal ohms for a solution of $2.3 \mathrm{~g}$ in $100 \mathrm{~g}$ of water, at $30^{\circ}$ ) it was washed with four more changes of distilled water (conductivity $1 \times$ $\left.10^{-6}\right)$. This raised the $\mathrm{pH}$ of the gelatin to 5.4. The air-dry material was found to contain 13 per cent moisture when dried at $105^{\circ}$ to $110^{\circ}$. All solutions were made up with $1.150 \mathrm{~g}$ of air-dry gelatin to $100 \mathrm{ml}$.

The hydrogen ion concentration was adjusted by appropriate amounts of sulphuric acid or (carbonate-free) sodium hydroxide. The titration curve is reproduced in Figure 2. Mixtures were found to be readily reproducible to less than $0.1 \mathrm{pH}$ unit except on the steepest part of the curve, around $\mathrm{pH} 7$, where the error may have reached 0.2 . 
The equilibrium measurements were first made on three series of mixtures, each series containing a constant amount of silver nitrate and gelatin at varying $\mathrm{pH}$. Attempts to carry the measurements to higher silver concentrations $\left(10^{-2} \mathrm{~N} \mathrm{AgNO}_{3}\right)$ were unsuccessful. The electrodes were very readily. poisoned, apparently by coagulated gelatin, and as the changes in concentration were smaller, the results were much less reliable. The data for silver ion activities in mixtures of $1.00 \mathrm{~g}$ gelatin per $100 \mathrm{ml}$ over a range of $\mathrm{pH} 2.4$ to 9.5 and a range of $\mathrm{AgNO}_{3}$ normality $10^{-3}$ to $10^{-5}$, are given in Table 1 . Table 2 gives the data for mixtures at $\mathrm{pH} 7.0,10^{-3}$ and $10^{-4} \mathrm{~N} \mathrm{AgNO}_{3}$ and varying gelatin concentration.

Some measurements were made on mixtures of gelatin and bromide solutions on the acid side of the isoelectric point where the combination of silver ion and gelatin was relatively small, in an attempt to detect possible combination of bromide ion and gelatin. The changes in potential were small and erratic, the electrodes readily becoming poisoned. Any combination of bromide ion and gelatin is apparently much weaker than that of silver ion and gelatin, even on the acid side of the isoelectric point. In the electrode readings in emulsions, which are kept in equilibrium with silver bromide by the large amount of finely divided solid, the potentials were steady and reproducible, with little tendency to poison the electrodes.

TABLE 1.-Activity of silver ion in mixtures of silver nitrate and gelatin

$1.00 \mathrm{~g}$ gelatin per $100 \mathrm{ml}$ in all mixtures; silver nitrate and hydrogen ion concentrations varied

\begin{tabular}{r|r|r|r|r|r|r|r}
\hline & \multicolumn{7}{|c}{ Activity of silver ion in mixture, at pH } \\
Concentration of \\
AgNO3 in mixture,
\end{tabular}

\begin{tabular}{|c|c|c|c|c|c|c|c|}
\hline \multirow{2}{*}{$\begin{array}{c}\text { Concentration of } \mathrm{AgNO}_{8} \text { in } \\
\text { mixture, } N\end{array}$} & \multicolumn{7}{|c|}{ Activity of silver ion in mixture, at $\mathrm{pH}$} \\
\hline & 6.5 & 7.0 & {$[7.5$} & 8.0 & $8.5 !$ & 9.0 & 9.5 \\
\hline $1.00 \times 10^{-3}$ & $\begin{array}{r}2.65 \\
\times 10^{-4}\end{array}$ & $\begin{array}{r}2.42 \\
\times 10^{-4}\end{array}$ & $\begin{array}{r}2.20 \\
\times 10^{-1}\end{array}$ & $\begin{array}{r}1.55 \\
\times 10^{-1}\end{array}$ & $\begin{array}{r}1.1 \\
\times 10^{-4}\end{array}$ & $\begin{array}{r}4.3 \\
\times 10^{-3}\end{array}$ & $\begin{array}{r}1.17 \\
\times 10^{-5}\end{array}$ \\
\hline $9.7 \times 10^{-3}$ & 9.4 & 6.0 & 3.6 & 2.4 & 1.5 & 8.4 & \\
\hline $1.04 \times 10^{-5}$ & $\times 10^{-i}$ & $\begin{array}{r}\times 10^{-7} \\
1.45\end{array}$ & $\begin{array}{r}\times 10^{-7} \\
90\end{array}$ & $\begin{array}{r}\times 10^{-7} \\
5,6\end{array}$ & $\times 10^{-7}$ & $\times 10^{-8}$ & $\begin{array}{r}\times 10^{-8} \\
9\end{array}$ \\
\hline & & $\times 10^{-8}$ & $\times 10^{-0}$ & $\times 10^{-0}$ & $\times 10^{-0}$ & $\times 10^{-1}$ & $\times 10^{-10}$ \\
\hline
\end{tabular}

TABLE 2.-Silver ion activity in mixtures of silver nitrate and gelatin $\mathrm{pH}$ constant at $\mathbf{7 . 0}$; gelatin and silver nitrate concentrations varied

\begin{tabular}{|c|c|c|}
\hline $\begin{array}{c}\text { Concen- } \\
\text { tration of } \\
\text { gelatin, } \\
\text { g per } 100 \mathrm{ml}\end{array}$ & \multicolumn{2}{|c|}{ Silver ion activity } \\
\cline { 2 - 3 } & $\begin{array}{c}\text { Silver nitrate } \\
9.7 \times 10^{-4} \mathrm{~N}\end{array}$ & $\begin{array}{c}\text { Silver nitrate } \\
9.7 \times 10^{-6} \mathrm{~N}\end{array}$ \\
\hline 1.00 & $2.4 \times 10^{-4}$ & $6.0 \times 10^{-7}$ \\
.50 & $5.1 \times 10^{-4}$ & $3.6 \times 10^{-6}$ \\
.25 & $7.0 \times 10^{-4}$ & $1.65 \times 10^{-6}$ \\
.125 & $7.8 \times 10^{-4}$ & $4.3 \times 10^{-6}$ \\
.063 & $8.7 \times 10^{-4}$ & $\mathbf{6 . 1} \times 10^{-6}$ \\
\hline
\end{tabular}




\section{DISCUSSION}

Results for both series of measurements of silver nitrate-gelatin solutions are presented in Figure 3, calculated as gram equivalents of silver combined with one gram of gelatin. In making the calculations, the silver ion concentrations have been computed from the

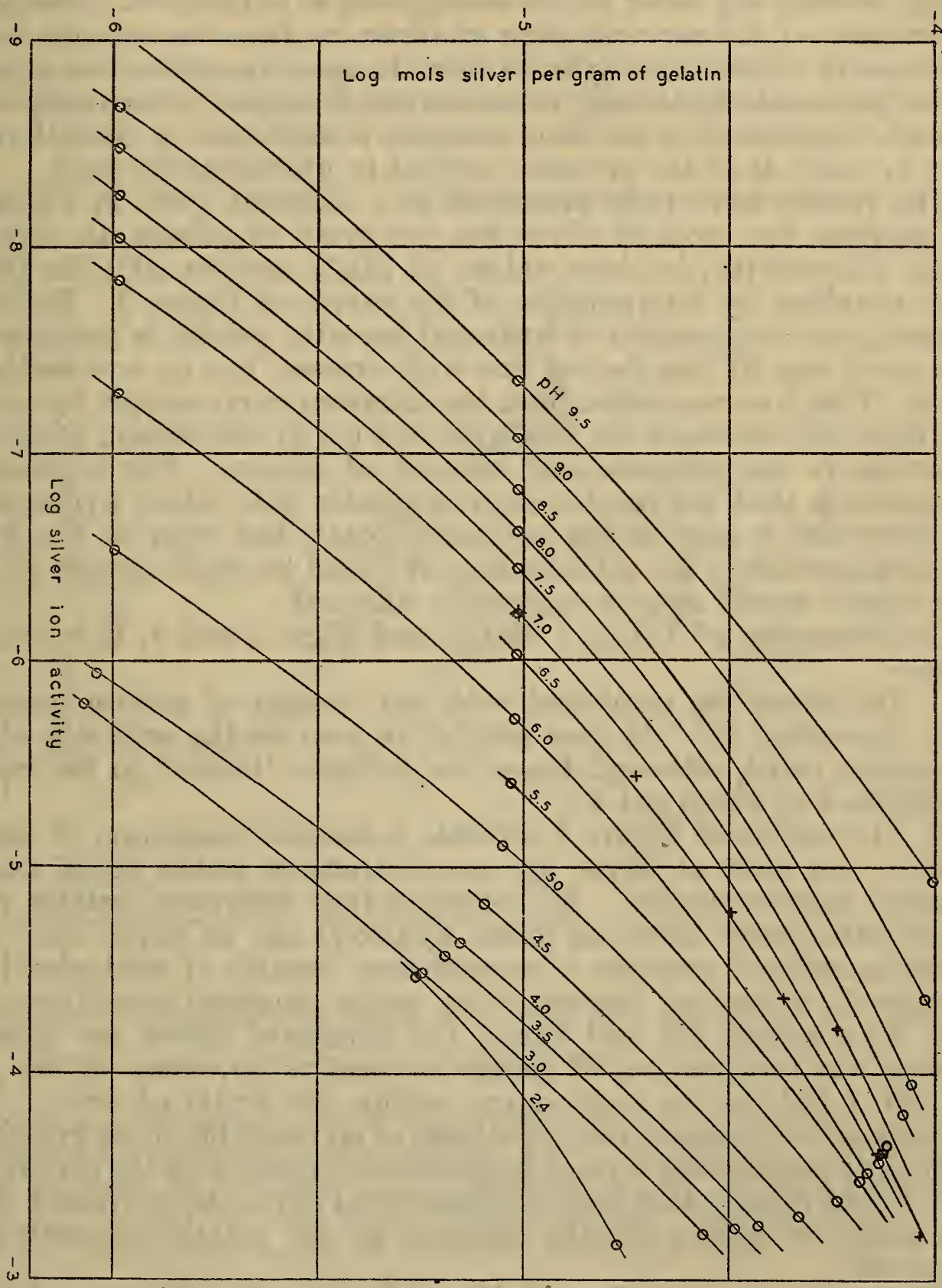

FIGURE 3.-Combination of silver ion and gelatin at $30^{\circ}$. Circles represent determinations at a concentration of $1.00 \mathrm{~g}$ per $100 \mathrm{ml}$; crosses, determinations at other gelatin concentrations and $\mathrm{pH} 7$

activities by means of the ionic strength tables given by Lewis and Randall. ${ }^{12}$ They were practically identical except in the more acid mixtures, which contained up to $0.015 \mathrm{~N} \mathrm{H}_{2} \mathrm{SO}_{4}$. In making this com- 
putation, we are using the same assumption as Northrop and Kunitz, ${ }^{13}$ that the gelatin does not affect the ionic strength. To put it differently, the complex gelatin-hydrogen ion affects the ionic strength by the same amount as the hydrogen ion, so that it is the same in the gelatin-acid mixture as in the pure acid. In this case the contribution of the bivalent sulphate ion to the ionic strength is much the larger, so that any error in the assumption is minimized. The whole calculation of the concentration of silver ion from its activity in the presence of other electrolytes is open to some question, but appears to be preferable to the use of uncorrected values. As already mentioned, the correction for ionic strength is negligible in the $\mathrm{pH}$ range 5 to 9 , which is of the greatest interest in photographic work.

The results have been presented in a different form in Figure 4, by plotting the mols of silver ion per gram of gelatin at constant silver ion activity, for four values of $\left[\mathrm{Ag}^{+}\right]$, against $\mathrm{pH}$; the points were obtained by interpolation of the curves of Figure 3. For comparison, the combination of hydroxyl ion with gelatin is presented in the same way by the dashed line with crosses, but on one-tenth the scale. This was computed from the titration curve simply by taking the difference between the free hydroxyl ion in the sodium hydroxide solutions in the presence and absence of gelatin. The implied assumption is that the combination of gelatin with either hydrogen or hydroxyl ion is zero at the isoelectric point, but even on the hypothesis suggested in the introduction, it would be small enough so that the values would not be materially affected.

On inspection of Tables 1 and 2 , and Figs. 3 and 4 , it is evident that-

1. The silver ion combined with unit weight of gelatin increases with increasing $\mathrm{pH}$. It does not fall to zero on the acid side of the isoelectric point, although there is a definite "break" in the curves of Figure 4 at about $\mathrm{pH} 4.7$.

2. The curves of Figure 3 indicate a possible maximum of combination, but only at silver ion concentrations which could not be reached experimentally. At corresponding activities, gelatin combines with many times as much hydroxyl ion as silver ion. The silver ion-gelatin reaction is nevertheless capable of producing large changes in silver ion concentration under emulsion conditions.

3. At constant $\mathrm{pH}$ and $\left[\mathrm{Ag}^{+}\right]$, the combined silver per gram of gelatin was independent of gelatin concentration, since all the data for $\mathrm{pH} 7$ fall on the same curve within the limits of error. This permits us to eliminate the hypothesis of an insoluble silver gelatinate of definite proportions formed in amounts varying with the conditions, as it would require that with constant total silver the combined silver per gram of gelatin should increase as the gelatin concentration decreased.

The nearly straight lines of Figure 3 show that the combination closely follows the adsorption isotherm. The value of $1 / \mathrm{n}$ is somewhat higher than usual, varying from 0.5 at $\mathrm{pH} 9$ to 0.6 at $\mathrm{pH} 3$. In the present state of colloid chemistry, it is hardly worth while to discuss, on the basis of the available evidence, whether this combination is to be designated as selective adsorption or as chemical combination. The silver is probably attached to the amino groups of the gelatin,

\footnotetext{
18 Reforence 2.
} 
since the silver-ammonia ion is not adsorbed. (Sec. III of this paper.) It will be noted that the "break" in the curves of Figure 4 at the isoelectric point becomes more pronounced with increasing silver ion concentration, so that the combination more nearly approaches the prediction of the simple chemical theory.

It is probable that the decrease in silver ion activity produced by the gelatin tends to stabilize the emulsion from the photographic standpoint, retarding the reduction or other reactions of the silver ion. Reaction by rearrangement of the silver ion-gelatin complex is, of course, possible but likely to be slower. Photographic evidence will be considered in connection with the equilibrium in emulsions.

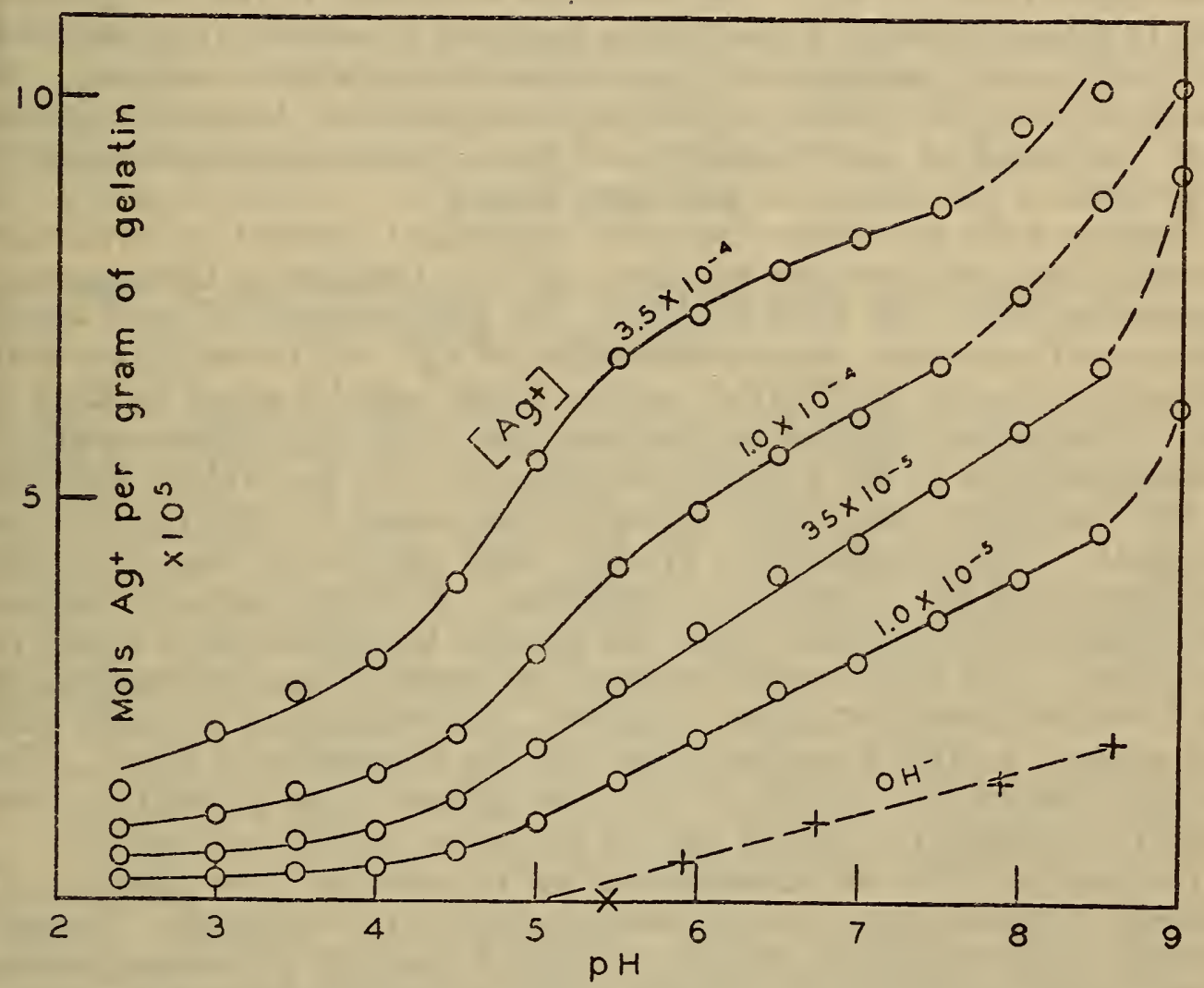

FIGURE 4.-Change in combination of silver ion and gelatin with $p H$

Crosses represent combination of hydroxyl fon and gelatin, on one-tenth the scale

As the combination is quite appreciable even at the silver ion concentration of saturated silver bromide $\left(10^{-6} \mathrm{~N}\right.$ at $\left.30^{\circ}\right)$, the solubility of silver bromide is increased in the presence of gelatin by an amount depending on the $\mathrm{pH}$ and gelatin concentration. Experiments under emulsion conditions indicate that it can easily reach $4 \times 10^{-5} \mathrm{~N}$ as against $1.0 \times 10^{-6} \mathrm{~N}$ in pure water.

\section{EQUILIBRIUM IN SILVER BROMIDE-AMMONIA- GELATIN SOLUTIONS}

Since ammonia is added to many emulsions for the purpose of accelerating the ripening process, the equilibrium between the gelatin and the dissolved silver salts is of considerable interest. This was also investigated by e. m. f. measurements in the same apparatus, as 
it was found reliable readings for bromide ion concentration could be obtained in the presence of ammonia provided that care was taken to keep the solution saturated with silver bromide. A small closed cell, without stirrer, was found to be satisfactory. The assumption is made that the presence of the ammonia does not change the solubility product of silver bromide, that is, that there is no change of solvent. This appears to have been justified.

The necessary data, which are given in Table 3, consisted simply of determinations of the bromide ion concentration in ammonia solutions of varying concentrations, saturated with silver bromide. The solutions were made up in pairs, with and without the addition of 1.00 gram gelatin per $100 \mathrm{ml}$. The solutions were kept in the $30^{\circ}$ thermostat, in glass-stoppered Pyrex flasks, agitated at intervals and sampled every day until readings on three successive days were constant. In the presence of the gelatin, which peptized the silver bromide, equilibrium was reached more rapidly and was apparently not affected by hydrolysis of the gelatin as had been feared.

Starting with pure silver bromide, equivalent amounts of silver and bromide ions must go into solution, and the product of their concentrations at $30.0^{\circ}$ will be $9.2 \times 10^{-13}$. In the presence of even small amounts of ammonia, the concentration of $\mathrm{Ag}^{+}$will be negligible with respect to that of $\mathrm{Ag}\left(\mathrm{NH}_{3}\right)_{2}{ }^{+}$, so the latter will be equal to that of $\mathrm{Br}^{-}$. The measurements on the solutions without gelatin constitute a determination of the equilibrium between $\mathrm{Ag}^{+}, \mathrm{Ag}\left(\mathrm{NH}_{3}\right)_{2}{ }^{+}$and $\mathrm{NH}_{3}$ at $30^{\circ}$, and give reasonably reproducible values for the equilibrium constant. The combination of $\mathrm{Ag}^{+}$with gelatin at the silver ion activities in these solutions, is negligible. If there were appreciable combination of $\mathrm{Ag}\left(\mathrm{NH}_{3}\right)_{2}{ }^{+}$with the gelatin, the equilibrium would be disturbed, with consequent increase in bromide ion concentration. As is evident from inspection of table 3 , the readings of the cells with and without gelatin were the same with the experimental error. The combination of the $\mathrm{Ag}\left(\mathrm{NH}_{3}\right)_{2}{ }^{+}$ion with gelatin must at least be very small compared with that of $\mathrm{Ag}^{+}$at the same activity and $\mathrm{pH}$.

The failure of the silver-ammonia ion to combine with gelatin is of interest in connection with ammonia ripening of emulsions. During ripening before washing, soluble bromide is present in concentrations of the order of 0.02 to $0.1 \mathrm{~N}$; the silver ion concentration is correspondingly small $\left(10^{-9} \mathrm{~N}\right.$ or less, depending on temperature). Adding ammonia under these conditions, the amount of silver bromide which can go into solution is negligible with respect to the soluble bromide present; the bromide and silver ion concentrations are therefore practically unchanged. The silver ion bound to gelatin will increase because of the increased alkalinity, but must remain very small. The increased solubility of silver bromide results in increased rate of change of grain size, but the silver-ammonia ion is quite unlikely to undergo direct reaction to silver or silver sulphide. The increased rate of formation of sensitizing nuclei in the presence of ammonia is therefore to be ascribed to the increased alkalinity. 
TABLE 3.-Equilibrium at $30.0^{\circ}$ in ammonia solutions saturated with silver bromide, with and without gelatin

\begin{tabular}{|c|c|c|c|c|}
\hline $\begin{array}{c}\text { Ammonia } \\
\text { concentra- } \\
\text { tion } N\end{array}$ & $\begin{array}{c}\text { E. m. f. of } \\
\text { cell (silver } \\
\text { electrode } \\
\text { negative) }\end{array}$ & $\begin{array}{c}\text { Bromide-ion } \\
\text { concentration }\end{array}$ & $\begin{array}{c}\text { Equilibrium } \\
\text { constant } \\
{\left[\mathrm{Ag}^{+}\right] \times\left[\mathrm{NH}_{3}\right]^{2}}\end{array}$ & $\begin{array}{c}\text { E. m. f. of } \\
\text { cell with } \\
\text { gelatin }\end{array}$ \\
\hline & $\mathrm{Ag}^{\left.\mathrm{Ag}\left(\mathrm{NH}_{3}\right)_{2} \mathrm{z}^{+}\right]}$ & & & \\
\hline 0.05 & 0.0366 & $1.75 \times 10^{-4}$ & $7.5 \times 10^{-8}$ & 0.0365 \\
.10 & .0550 & $3.5 \times 10^{-4}$ & $7.4 \times 10^{-8}$ & .0539 \\
.20 & .0726 & $7.0 \times 10^{-4}$ & $7.5 \times 10^{-8}$ & .0716 \\
.40 & .0909 & $1.41 \times 10^{-8}$ & $7.3 \times 10^{-8}$ & .0887 \\
.80 & .1082 & $2.73 \times 10^{-3}$ & $7.9 \times 10^{-8}$ & .064 \\
\hline
\end{tabular}

These data, it will be noted, apply to the addition of ammonia to liquid emulsions. When dried emulsions on photographic plates are bathed in ammonia solutions, as in hypersensitizing, the resulting equilibrium involves other factors. This will be discussed in a separate communication on hypersentization.

\section{THE CONPOSITION OF EMULSIONS WASHED TO EQUILIBRIUM}

Under practical conditions, the washing of a photographic emulsion is carried only far enough to reduce the soluble bromide below a predetermined value. The test commonly recommended is to add silver nitrate to a sample, with potassium chromate as indicator. The minimum amount of soluble bromide which can be detected in this way must be very large compared to the bromide-ion concentration of saturated silver bromide. Most commercial emulsions as coated contain soluble bromide in a molar ratio $3-10$ to 1,000 of silver bromide, although this may have been added after washing.

It is common knowledge ${ }^{14}$ that emulsions which have been washed too thoroughly are liable to fog. We have already ${ }^{15}$ presented data on the effect of bromide-ion concentration during after-ripening which illustrates this.

Recently Schmidt and Pretschner ${ }^{16}$ have analyzed thoroughly washed emulsions by digestion with nitric acid and gravimetric determination of the soluble silver in the filtrate. They originally considered that this was metallic silver, formed by reduction of the silver halide during the preparation of the emulsion, but correctly decided that it could not be identified with the ripening nuclei, since there was no correlation between the amount of excess silver and the sensitivity. They have since, ${ }^{17}$ on the basis of other evidence, realized that the silver was not present as metal but in combination with the gelatin. They found that the amount of excess silver increased with the solubility of the silver salt. Recalculating their results reported in reference 16 to gram equivalents of silver per gram of gelatin, on the assumption that their emulsions contained about 1.6 grams gelatin per gram of silver bromide, they found that the excess silver varied from zero in silver iodide emulsions to 3 to $4 \times 10^{-6}$ in silver bromide

${ }^{14}$ Wall, Photographic Emulsions, p. 145. Eder-Wentzel, Die Fabrikation der photographischen Platten * *, p. 127.

18 Carroll and Hubbard, B. S. Jour. Research, vol. 7, p. 219; 1931.

16 Schmidt and Pretschner, Zs. wiss. Phot., vol. 25, p. 293; 1928.

${ }^{17}$ Reference 6. 
emulsions, and $2 \times 10^{-5}$ in silver chloride emulsions. They used $700 \mathrm{~g}$ samples of emulsion "noodles," which had been washed 10 hours in running tap water, then 24 hours in distilled water, the washing being continued 4 to 5 hours after the washings gave no turbidity with silver nitrate. This is much more thorough than any practical emulsion washing, but as the emulsion was in "noodles" several $\mathrm{mm}$. thick, it is almost certain that it did not reach complete equilibrium with the wash water.

In their most recent communication, ${ }^{18}$ which is available only in abstract, they report that on sufficiently long washing the excess silver tended to decrease; this was not observed in any of the experiments in this laboratory. This was attributed to the difference in solubility of the silver halide grains of commercial brom-iodide emulsions, produced by differences in size and composition. The effect of size per se seems unlikely to be appreciable, but the smaller and larger grains of a brom-iodide emulsion differ widely in percentage of iodide ${ }^{19}$ in such a way that the size effect may be enormously accentuated. However, even the smallest and most soluble grains would be removed only on very extensive washing.

If pure silver bromide dispersed in a gelatin jelly is allowed to come to equilibrium with water, the resulting bromide-ion concentration will be higher than that of saturated silver bromide, since silver ion will combine with gelatin, and the equivalent amount of bromide ion will remain in solution. The silver ion in combination with the gelatin will, therefore, be less than corresponds to the silverion concentration of saturated $\mathrm{AgBr}$. If the wash water is repeatedly changed, removing the soluble bromide, the gelatin will ultimately come to equilibrium with the silver-ion concentration of saturated silver bromide, and further washing will remove $\mathrm{Ag}^{+}$and $\mathrm{Br}^{-}$in equivalent amounts. At $30^{\circ}$ and $\mathrm{pH} 7$, for example, this corresponds to $1.2 \times 10^{-5} \mathrm{~g}$ equivalents of $\mathrm{Ag}^{+}$per $\mathrm{g}$ of gelatin; the amount will vary with the temperature and $\mathrm{pH}$.

Our first experiments on the effect of continued washing on the excess of silver over bromide were made to check the results of Schmidt and Pretschner, and the emulsions were extracted with 3 per cent $\mathrm{HNO}_{3}$ according to their method. Working with the emulsion stripped from 5 by 7 inch plates, electrometric titration of the extract with $0.0010 N \mathrm{KBr}$ was substituted for gravimetric analysis, with complete satisfaction.

It was found, in this way, that both with commercial and experimental emulsions, the excess silver became constant only after plates had been washed in running tap water for about 20 hours; washing is obviously much more rapid in the very thin coating of a plate than in emulsion noodles. The constant value obtained this way was 1.4 to $1.5 \times 10^{-5} \mathrm{~g}$ equivalent $\mathrm{Ag}^{+}$per g gelatin, at a $\mathrm{pH}$ of 8 to 8.5. This amounts to 0.4 per cent of the total silver in the plate.

It was later found ${ }^{20}$ that the excess silver could be determined by extraction with dilute acid, or by simply acidifying the stripped emulsion to $\mathrm{pH} 2$ to 3 , thus reducing the silver ion-gelatin combination and making a direct electrometric titration without extraction.

1. Reference 6.

11 Reawick and Sease, Phot. J., vol. 64, p. 380; 1924.

10 Preliminary note in Technical News Bulletin of Bureau of Standards, September, 1930. Details will be given in a separate communication on analysis of emulsions for excess silver or bromide. 
This method was used in further washing experiments which gave a satisfactory check with the equilibrium values obtained in solution.

Experimental emulsions were made up with pure silver bromide and chloride and coated in known amounts per unit area. The plates were washed for 48 hours in running tap water and for 24 hours in frequent changes of distilled water, both at $20^{\circ}$. The stripped emulsions were then acidified and titrated, using $0.0010 \mathrm{~N}$ $\mathrm{KBr}$ for the bromide emulsion and $0.010 \mathrm{~N} \mathrm{KCl}$ for the chloride emulsion.

At $20^{\circ}$ the silver-ion concentration of saturated silver bromide is $5.5 \times 10^{-7} \mathrm{~N}$; at this concentration and $\mathrm{pH} 8$ gelatin is in equilibrium with $1.4 \times 10^{-5} \mathrm{~g}$ equivalent $\mathrm{Ag}^{+}$per $\mathrm{g}$ (Figure 3). In the washed plates, the values found by titration were $1.79,1.76 \times 10^{-5}$. Similarly, for saturated silver chloride at $20^{\circ}$, the silver-ion concentration is $1.05 \times 10^{-5} \mathrm{~N}$; the $\mathrm{Ag}^{+}$per g gelatin at $\mathrm{pH} 8$ is $4.1 \times 10^{-5} \mathrm{~g}$ equivalents by Figure 3 and $3.2,3.1 \times 10^{-5}$ by titration of the washed plates.

\section{SUMMARY}

1. The equilibrium between silver ion and gelatin has been studied by the silver electrode over a considerable range of silver and hydrogen-ion concentrations. Gelatin may cause large changes in silverion concentrations under conditions similar to those in photographic emulsions.

2. No combination of gelatin with the silver-ammonia ion was detected.

3. Prolonged washing of silver bromide or chloride gelatin emulsions causes appreciable hydrolysis of the silver halide, leaving the emulsion with analytically detectable excess silver in combination with the gelatin.

WASHINGTON, September 22, 1931. 